\title{
Social Role Conceptions and CSR Policy Success
}

\section{Tobias Gössling Chris Vocht}

\begin{abstract}
Businesses are eager to present themselves as honest and reliable corporate citizens who care about the overall well-being of society. This article researches whether different role conceptions of businesses regarding social issues are related to their success in dealing with social demands. Do socially active companies have a better social reputation than inactive companies? This relationship is determined by first extracting the social role conceptions of the companies from their Corporate Social Responsibility reports and then comparing this data to their social reputations. The analysis shows that there is indeed a relationship between these two variables. Companies with a broad social role conception score significantly better on their social reputations than companies with a narrow role conception. Social role conceptions therefore matter when dealing with social demands.
\end{abstract}

KEY WORDS: social role conception, CSR, corporate social performance, legitimacy

\section{Introduction}

Corporate Social Responsibility (CSR) is about the basic idea that businesses have to meet society's expectations in their practices. Nowadays, businesses

Tobias Gössling is Assistant Professor in the department of Organisation Studies at Tilburg University, The Netherlands. He obtained his PhD in political science at Witten/ Herdecke University. He has experience in consultancy, both for profit organisations and for organisations of research and higher education. His current research focuses on institutions, network organisations and Corporate Social Responsibility.

Chris Vocht is currently working as a Business Intelligence consultant at Royal DSM N.V. He recieved his Master's degree in social science at Tilburg University, The Netherlands. operate in an environment in which societal concerns have been raised to a considerable level. CSR can be seen as an obligation of the business world to be accountable to all of its stakeholders - not just its financial ones. This idea is far from new.

Upto date, there is still no legally binding global code of conduct for multinational corporations or for foreign direct investment (Mah, 2004). This means that the practice of Corporate Social Responsibility is still a largely voluntary act and subject to self-regulation. There are initiatives to come to international standards, like the UN Global Compact and the ISO 14001 environmental standard, but corporations can decide for themselves whether to adhere to them or not. Furthermore, a unanimous definition of CSR does not exist. This has resulted in difficulties when applying strict standards or sanctions to firms that do not comply with codes (Mah, 2004).

Consumers increasingly base their opinion of a business on factors like treatment of employees, community involvement and environmental issues, instead of traditional factors like product quality, value for money and financial performance (Dawkins and Lewis, 2003). In addition to this, there is a trend in business that in particular young and highly trained employees want a sense of purpose in their work (Colvin, 2001). They want to know that their work has a positive effect on the world.

The possibility for businesses to attract socially aware investors can be seen as a third reason to pay attention to their social responsibilities. Socially responsible investment has been popular in some circles over the past years, but nowadays the mainstream investment community also takes an active interest. In 1999 Dow Jones created the 'Dow Jones Sustainability indexes' and in London the 'FTSE4Good' was brought to life. These initiatives are grounded on the idea that businesses can make a 
decent profit while helping the environment and society at the same time (Doane and Abasta-Vilaplana, 2005).

Recent publications - e.g. Websites, advertisements, public statements - by leading corporations show that the business world has picked up the trend towards higher social demands from the public and that they are actively pursuing socially responsible images (Mah, 2004). Businesses are increasingly eager to present themselves as good corporate citizens and try to show a genuine interest in a variety of social issues, like the condition of the environment, the well-being of employees and the welfare of society at large (Maignan and Ferrell, 2003).

\section{Research problem}

This current research starts from the statement that the economic perspective of an organisation is crucial for the decision about getting involved with CSR and in which form (Moir, 2001). Firms can have different views on what their role in society should be and this has an influence on their involvement in social issues.

The initial focus of this research is to investigate, whether different businesses actually have different role conceptions about social issues. We have named this variable the "width of the role conception of a business' (WoRC). The second objective is to determine, whether a relationship can be found between the WoRC of a specific business and its success in dealing with social demands. Thus, the research question of this articleis the following: To what extent does the width of the role conception of globally active multinational businesses regarding their social responsibility relate to their success in dealing with social demands?

\section{Approach}

In order to determine this relationship, we conducted a quantitative study. In addition to this, qualitative data sources were analysed and coded to supply this data. We define the success in dealing with social demands from the legitimacy theory. Suchman $(1995,475)$ defines legitimacy as "a generalised perception or assumption that the actions of an entity are desirable, proper or appropriate within some socially constructed system of norms, values and definitions." This definition implies that a company can achieve legitimacy by giving society the impression that it acts as a good 'corporate citizen.' This also means that the perception of society about a company's actions is decisive for legitimacy evaluations, not the actions themselves. We therefore define the success of a company in dealing with social demands as the reputation that a company has amongst society regarding these issues. The actual practical successes of a company, like environmental or societal achievements, do not fall under the scope of this research.

To determine the success of businesses in dealing with the demands society places on them, we used the data set from Fortune magazine's 'Global Most Admired Companies' research. The research is annually conducted by the Hay Group (http:// www.haygroup.com/About). The Fortune Most Admired Companies study surveys top executives and directors of the companies on the list to identify the companies that enjoy the strongest reputation within and across their industries. Fortune magazine's research on corporate reputations is well accepted as a data source for CSR research (Sharfman, 1996).

Fortune magazine publishes two separate lists: the America's Most Admired Companies list and the Global Most Admired Companies list. In order to avoid a nation-related bias, the current research uses the Global Most Admired Companies list. The survey is conducted amongst the executives of the largest companies in the world and has over 15,000 respondents. Per listed company a maximum of 10 executives and 7 directors are allowed to participate in the research. The overall reputation score is determined by 9 selected attributes, namely (1) ability to attract and retain talented people, (2) quality of management, (3) social responsibility to the community and the environment, (4) innovativeness, (5) quality of products or services, (6) wise use of corporate assets, (7) financial soundness, (8) long-term investment value and (9) effectiveness in doing business globally.

The results from the survey have led to a score from 1 to 10 on each of the attributes. In this specific research project the main focus is on attribute 3 : social responsibility to the community and the environment. The score on this attribute is used to determine the success of a company in dealing with 
its social demands - one of the two variables of this research. The research is based upon the 2004 survey data. The Fortune magazine data has the advantage that it is provided by presumably well informed managers of the listed companies. However, since there is no theory underlying the choice of variables, the validity of the results can be problematic (c.f. Sharfman, 1996). ${ }^{1}$

We developed the concept of role conception of a business regarding its social responsibilities as a variable. This variable is based upon Carroll's Social Performance Model (1979). Carroll (1979) poses four categories economic, legal, ethical and philanthropic - that in an exhaustive manner address the obligations of business to society. Carroll visualises this situation by using the categories as steps in a pyramid. This article uses these categories as an indicator for role conceptions of businesses. Businesses that solely focus on their financial and legal obligations have a 'narrow' role conception, while businesses that also focus on ethical and philanthropic responsibilities have a 'broad' role conception. This leads to the following definition for the WoRC: "The level of attention of a company on economic and legal responsibilities and the level of attention on ethical and philanthropic responsibilities'.

In order to determine the WoRC, we analysed their CSR reports. Even though there is no legally binding obligation for companies to report on their social responsibilities, more and more companies publish reports that address these issues. Most companies annually publish a separate 'social' report in which they, for instance, state what contribution they have made to society or what efforts they have taken to protect the environment. Each company uses different names for these reports: some call it a 'social responsibility report' (e.g. Lowe's), others call it a 'sustainability report' (e.g. Fiat, UPS, Royal Ahold), and some call it an 'Environmental, Health and Safety report' (e.g. Deere). Regardless of the name of the report, the general purpose seems similar: companies use them to communicate to society that they care about issues like the well-being of their environment, their employees and/or society in general. By reporting on their activities to improve the well-being of society, they try to show that they are good and productive 'corporate citizens,' worthy of society's trust.

Such reports are merely self-presentations of businesses about their social responsibilities and they do not necessarily show what they actually do to improve society. As such, these reports may as well be window dressing. There are, however, reasons to be optimistic about the reliability of the CSR reports. Most companies that publish a CSR report treat it the same way as they treat their financial reports. This means that most reports are introduced by a signed letter from the president of the company. Furthermore, third-party involvement is a recent phenomenon in this context. In many cases, external auditors produce or control these reports. The examples of Mitsubishi, Enron and Royal Ahold show the possible consequences of intentionally misleading the public. We therefore assume that the CSR report presents a reasonably reliable picture of what a company regards as its social responsibilities and that there is a significant commitment present for meeting these responsibilities.

A content analysis on the CSR reports determines the WoRC of the companies. Content analysis is a common research technique in CSR Research (Gray et al., 1995). It can be defined as a systematic, replicable technique for compressing many words of text into fewer content categories based on explicit rules of coding (Weber, 1990). Furthermore, content analysis is an appropriate technique for making deductions by using systematic methods for the analysis of texts and other messages. (Stemler, 2001).

The coding of a written document always poses a challenge when pursuing both a high validity and a high reliability (Weber, 1990). The unit of analysis for the content analysis of written documents tends to be words, sentences or pages (Gray et al., 1995). In the case of this research a highly reliable way of analysing the CSR report would, for instance, be to count the number of times a word referring to social responsibility appears in the document. This approach is challenging for several reasons. First, it is hardly possible to exactly define which words refer to social responsibility. Second, single words - taken out of their contexts - do not necessarily exactly reflect the role conception of a business.

This research uses statements about social responsibility as a unit of analysis. The data consist of sentences and statements and their contexts. The statements are used to determine the 'level of attention' to the different types of responsibilities of a company. This indicator is logically derived from the definition of the WoRC that is used in this research. 
As Carroll (1979) states, the four categories of the Social Performance Model - economic, legal, ethical and philanthropic - are not mutually exclusive. This means that motives for actions can at once be driven by economic, legal, ethical and philanthropic motives. In order to make a clear distinction between the different motives, the coding focused on the primary type of responsibility. This means that when a statement is considered to primarily refer to the ethical responsibilities of a company, there can still be economic, legal or philanthropic considerations that have played a role.

After reading the selected CSR reports, the reports were again scanned for statements that directly or indirectly refer to one or more of the company's stakeholders. These statements were extracted from the reports and then placed on a list for each company. The lists were reviewed and all the statements that could not be connected to one of the four categories of Carroll's model - economic, legal, ethical and philanthropic - were removed.

The next step of the research was to determine for each statement to which type of responsibility it referred. The research makes use of a question flowchart in order to achieve a reliable and reproducible allocation. The flow chart consists of several questions that point to a certain type of responsibility. Each question starts with: "Is the statement primarily aimed at..." and ends with a certain characteristic of the statement. The basic idea is that each statement starts at the top of the flow chart and then moves down through the questions. In case of a negative answer, the statement moves down to the next question for evaluation; in case of a positive answer the process stops. Each question points to one of the four types of responsibilities, so after answering a question positively, the actual allocation automatically takes place. For example, the following statement: "The world expects rugged, reliable machines from us" (Caterpillar sustainability report, p. 2) is compared with the first question of the flow chart: "Is the statement primarily aimed at the satisfaction of certain societal market needs by producing products or services by the company?" In case of a positive answer, the statement is marked as referring to an economic responsibility. In case of a negative answer the second question of the flow chart is used, and so on.

The questions in the flow chart were developed by using both a deductive and an inductive strategy.
First, the theoretical definitions that Carroll uses for the different types of responsibilities were carefully analysed and used as a starting point for a brainstorming session. The goal of the brainstorming session was to come to a variety of focal points for each type of responsibility that companies may have when posing a statement in their CSR report. Examples of focal points could, for instance, be 'product quality' or 'adherence to laws.' The researchers conducted three test runs on the flow chart. Thereafter, some questions were added to the flow chart and some were nominated to be removed. This procedure was iterated until saturation.

To test whether the flow chart is a reliable measuring instrument, we held an inter-coder reliability test. In this analysis, the responsibility allocations of the primary researcher were compared to responsibility allocations of a secondary coder on the basis of 146 statements. To analyse whether the allocations were significantly similar the Cohen's Kappa was calculated. Cohen's Kappa can be used as a measure for determining how often two researchers come to the same answer on the same questions (De Vocht, 2002).

As can be seen in Table I, the 'Symmetric Measures' table the Cohen's Kappa has a significant value of 0.814. According to De Vocht (2002), this means that there is a very high degree of similarity between the two lists of results by the two coders. Therefore, the flow chart is indeed a reliable tool for allocating the different types of responsibilities to the statements of the CSR reports of the researched companies. The data that were collected for this research were originally measured at a ratio level. For the WoRC, the data consist of the number of statements about a certain type of responsibility; in the case of the success in dealing with social demands, the scores from Fortune's research were used. The original data were transformed to an ordinal level of measurement.

This research makes a distinction between successful and unsuccessful organisations with respect to dealing with social demands. As a selection criterion for successful companies we used a score of 7 and higher; the criteria for unsuccessful companies was 4.5 and lower on the Fortune score. This selection led to a group of successful companies that consists of 41 units and the unsuccessful group consists of 28 cases.

In the next phase of the research, the statement lists of the selected companies were analysed. Every 
TABLE I

Inter coder reliability test

Case processing summary

\begin{tabular}{|c|c|c|c|c|c|c|c|c|}
\hline \multirow{3}{*}{ Original Check } & & \multicolumn{7}{|c|}{ Cases } \\
\hline & & \multicolumn{3}{|c|}{ Valid } & \multicolumn{2}{|c|}{ Missing } & \multicolumn{2}{|c|}{ Total } \\
\hline & & $\begin{array}{l}N \\
146\end{array}$ & & Percent & $\begin{array}{l}\mathrm{N} \\
0\end{array}$ & Percent & $\begin{array}{l}\mathrm{N} \\
146\end{array}$ & Percent \\
\hline \multicolumn{9}{|c|}{$\begin{array}{l}\text { Original Check Crosstabulation } \\
\text { Count }\end{array}$} \\
\hline \multirow{6}{*}{ Original } & \multirow{7}{*}{$\begin{array}{l}\text { Economic } \\
\text { Legal } \\
\text { Ethical } \\
\text { Philantrophic }\end{array}$} & \multicolumn{5}{|c|}{ Check } & \multicolumn{2}{|l|}{ Total } \\
\hline & & Economic & Legal & & Ethical & Philantropic & & \\
\hline & & 60 & 0 & & 0 & 1 & 61 & \\
\hline & & 1 & 11 & & 1 & 0 & 13 & \\
\hline & & 9 & 1 & & 41 & 3 & 54 & \\
\hline & & 2 & 0 & & 0 & 16 & 18 & \\
\hline $\begin{array}{l}\text { Total } \\
\text { Symmetric measures }\end{array}$ & & 72 & 12 & & 42 & 20 & 146 & \\
\hline $\begin{array}{l}\text { Measure of agreement } \\
\mathrm{N} \text { of valid cases }\end{array}$ & Карра & $\begin{array}{l}\text { Value } \\
.814 \\
146\end{array}$ & $\begin{array}{l}\text { Asymp } \\
.041\end{array}$ & d. Error ${ }^{\mathrm{a}}$ & $\begin{array}{l}\text { Approx. } T^{b} \\
15.104\end{array}$ & $\begin{array}{l}\text { Approx. Sig. } \\
.000\end{array}$ & & \\
\hline
\end{tabular}

${ }^{a}$ Not assuming the null hypothesis

${ }^{\mathrm{b}}$ Using the asymptotic standard error assuming the null hypothesis

statement was put through the flow chart and connected to one of the four types of responsibilities. A record sheet contains the selected scores for the companies and for each type of responsibility the total amount of statements that were connected to it. The analysis of the data in the record sheet consists of two phases. First, we calculated the relationship between the attention to each of the different types of responsibilities and the success in dealing with social demands. This potentially gives a valuable insight in the relationship between attention to a certain type of responsibility and the success in dealing with social demands.

Secondly, we calculated the relationship between the WoRC and the success in dealing with social demands. The outcome of this analysis answers the research question. Therefore, first, we converted the two variables to the same level of measurement. The absolute scores of the four different types of responsibilities were transformed to a three point scale: 'few', 'average' and 'many.' For each type of responsibility, separate criteria were developed to transform the absolute scores into scale scores. These criteria were derived from the average score per company and per type of responsibility and the standard deviation of the scores. Like with the allocation of companies to the successful group and the unsuccessful group no absolute statements can be made about whether a company has few or many statements about a certain type of responsibility. This is the reason that the companies were compared with each other and judged on a relative basis.

The five variables of this phase of the research are displayed in the conceptual model in Figure 1. This model does not imply any causal relationship between the variables but it merely shows about the connections between variables which are studied. In the second phase of the analysis, the relationship between the WoRC of the businesses and the success in dealing with social demands is calculated. To 


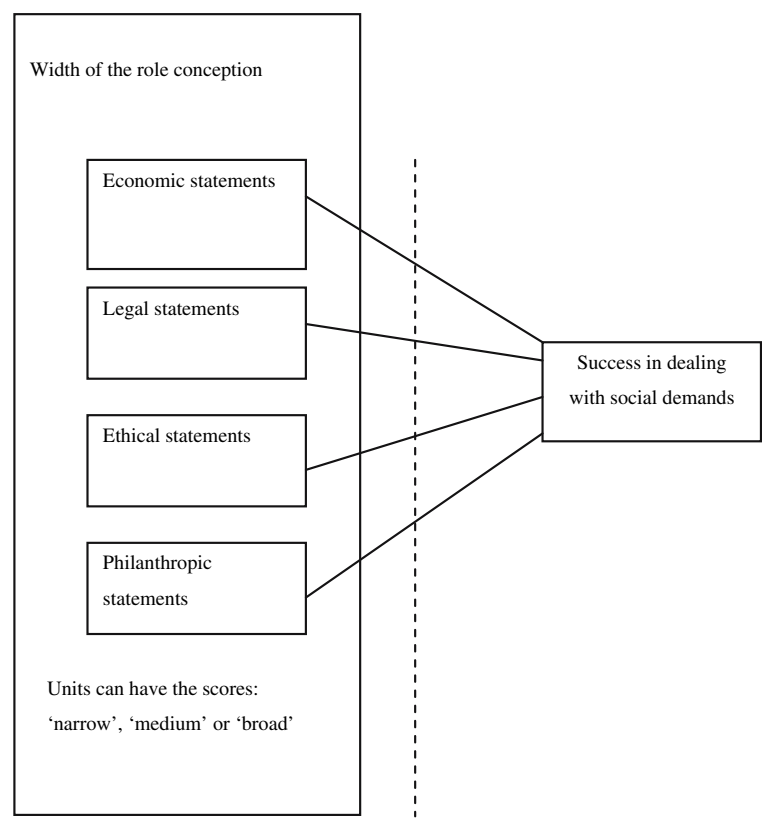

Figure 1. Conceptual model.

achieve this, first the individual scores in the four different types of responsibilities had to be converted to one score that represents the WoRC. For this conversion the categorical scores - few, average and many statements - from the first phase of the analysis were used.

A 'narrow' role conception is considered to be one that solely focuses on economic and legal responsibilities. A 'broad' role conception is one that also focuses on ethical and philanthropic responsibilities. Following this definition the scores on the economic and legal responsibilities and the scores on the economic and philanthropic responsibilities were combined. For determining the WoRC three levels were used: 'narrow', 'medium' and 'broad'. The criteria for the conversion were as indicated in Table II.

These criteria cover the individual scores of the two groups of responsibilities in an exhaustive manner. The relationship between the success in dealing with social demands and the WoRC is determined by using the Spearman's Rho correlation coefficient. The analysis is, like with the individual scores on the four types of responsibilities, performed using data on an ordinal level of measurement.

Most companies publish separate social responsibility reports in which they address their social obligations and report on their activities to
TABLE II

Conversion criteria

\begin{tabular}{lll}
\hline $\begin{array}{l}\text { With of the Role } \\
\text { Conception } \\
\text { (WoRC) }\end{array}$ & \multicolumn{2}{c}{ Score on the dimension } \\
\cline { 2 - 3 } & $\begin{array}{c}\text { Ethical/ } \\
\text { philanthropic }\end{array}$ & \multicolumn{1}{c}{$\begin{array}{c}\text { Economic/ } \\
\text { legal }\end{array}$} \\
\hline Narrow & Few & Few, average or many \\
& Average & Few \\
Medium & Average & Average \\
& Many & Few \\
Broad & Many & Average \\
& Average & Many \\
\hline
\end{tabular}

improve society. Even though there are great similarities between these reports, some companies use fewer words to describe the same policy and activities. When measuring the WoRC the length of the report should not influence the results. In order to avoid such bias, we performed a validity check on the size of the reports. The size of the report is measured by using the total number of pages of the report. Even though this measure is somewhat rough - page margins, font sizes, etc. also play a role in the size of the report - it should make significant validity problems visible.

In order to perform the validity, 40 companies were randomly selected from the total amount of researched companies. From these companies, both the WoRC and the total number of pages of their reports were analysed. Since the WoRC is measured on an ordinal scale, the numbers of pages were also converted to this scale. There is considerable variation in the total number of pages of the reports. However, this variation is not related to the WoRC of the companies. For example, PPG Industries, a company with a very small report, has a wide role conception, whereas Kmart, a company with a large report, has only a narrow role conception. In order to statistically prove the absence of a relationship between the size of the reports and the WoRC, we calculated the correlation between these two variables. However, there is no significant correlation between the two variables. Thus, the WoRC does not correlate with the size of the report. Hence, size of the report is not a moderating variable. 


\section{Data analysis}

The success in dealing with social demands was determined with the help of Fortune magazine's Most Admired Companies research. In this research each company received a score on a scale from one to ten that represents the strength of its reputation regarding its social responsibility to the community and the environment.

A total of 344 companies are listed in Fortune magazine's research. The best scoring company has a score of 8.40, the poorest scoring company a score of 2.42. The average score of 5.80 and the standard deviation of 1.00 indicates that most companies have a relatively average score on their social responsibility reputation. This is confirmed by the overview in Table III. It shows the number of companies for each category of CSR scores. As can be seen, most companies' CSR scores range between 5 and 7 .

A total of 22 countries have companies that meet the selection criteria of Fortune's research - a minimal annual revenue of 10 billion dollars. When looking at the average score on social responsibilities, the United States' companies have the highest average score on their CSR reputation; Mexico has the lowest average score. Mexico does, however, only have one listed company, so the score is entirely determined by this company. Other countries that score relatively low are China, South Korea and Russia.

The amount of attention to each type of responsibility was measured by applying the question flow chart to all the statements of the selected companies.

As can be seen in Table IV, a total of 69 companies' Social Responsibility Reports were analysed

\section{TABLE III}

Number of companies - CSR scores

\begin{tabular}{lcc}
\hline CSR score & $\begin{array}{c}\text { Number } \\
\text { of companies (total) }\end{array}$ & $\begin{array}{c}\text { Number } \\
\text { of companies (\%) }\end{array}$ \\
\hline $1-4$ & 8 & 2 \\
$4-5$ & 59 & 17 \\
$5-6$ & 142 & 41 \\
$6-7$ & 91 & 26 \\
$7-8$ & 37 & 11 \\
$8-10$ & 7 & 2 \\
\hline
\end{tabular}

TABLE IV

Summary 'width of the role conception'

\begin{tabular}{lrrrr}
\hline & \multicolumn{4}{c}{ Type of responsibility } \\
\cline { 2 - 5 } & Economic Legal & Ethical & Philanthropic \\
\hline Number of cases & 69 & 69 & 69 & 69 \\
Average score & 10 & 3 & 10 & 4 \\
St. deviation & 11 & 4 & 10 & 5 \\
Minimum value & 0 & 0 & 0 & 0 \\
Maximum value & 58 & 17 & 37 & 15 \\
\hline
\end{tabular}

in this research. The absolute scores on each type of responsibility were transformed to a three point scale: few, average and many statements about a certain type of responsibility. Each company received a score on each type of responsibility. Table $\mathrm{V}$ provides an overview about the amounts of statements.

A total of companies (52\%) in the research have a 'wide' role conception regarding social issues. Only $8(12 \%)$ of the companies have an average role conception, and 25 (36\%) have a narrow one. The relationship between the two variables in this research - the success in dealing with social demands and the WoRC regarding social issues - was determined by calculating the correlation between these variables. However, first the relationship between the attention to each of the four types of responsibilities and the success in dealing with social demands was determined. For this analysis the Spearman Rho's correlation coefficient was used. All variables are measured at the ordinal level.

Table VI shows the correlations between the attention of each company to the four different types of responsibilities and the success in dealing with

\section{TABLE V}

Number of companies - amount of statements

\begin{tabular}{lcccc} 
Amount $\begin{array}{l}\text { Af statements } \\
\end{array}$ & \multicolumn{4}{c}{$\begin{array}{c}\text { Type of responsibilities/number } \\
\text { of companies }\end{array}$} \\
\cline { 2 - 5 } & Economic & Legal & Ethical & Philanthropic \\
\hline Few & 28 & 36 & 29 & 35 \\
Average & 18 & 14 & 16 & 11 \\
Many & 23 & 19 & 24 & 23 \\
\hline
\end{tabular}


TABLE VI

Correlation success - different types of responsibilities

Correlations

\begin{tabular}{|c|c|c|c|c|c|}
\hline & & Economic resp. & Legal resp. & Ethical resp. & Philanthropic \\
\hline Spearman's rho & Correlation coefficient & $0.287 \star$ & 0.76 & $0.302^{\star}$ & 0.114 \\
\hline \multirow[t]{2}{*}{ Succes CSR } & Sig. (2-tailed) & 0.017 & 0.537 & 0.012 & 0.35 \\
\hline & $\mathrm{N}$ & 69 & 69 & 69 & 69 \\
\hline
\end{tabular}

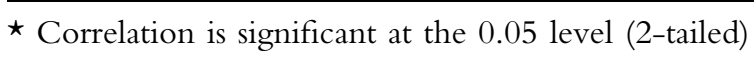

social demands. The results of the analysis show that the attention to economic and ethical responsibilities is significantly correlated to the success in dealing with social demands. The attention to economic responsibilities has a positive correlation of 0.287 and is significant at the 0.05 level. The attention to ethical responsibilities has a positive correlation of 0.302 and is also significant at the 0.05 level. The correlation between attention to legal responsibilities and philanthropic responsibilities and success in dealing with social demands is not significant.

Next the relationship between the WoRC regarding social issues and the success in dealing with social demands was determined. Again the Spearman Rho's correlation coefficient was used for this phase of the analysis.

As can be seen in Table VII there is a significant correlation between the role conception of a business and the success in dealing with social demands. The correlation coefficient measures 0.335 and is significant at the 0.05 level. The interpretation of these results is discussed in the next chapter of this report.

\section{Discussion}

The first goal of this research was to investigate whether different views on CSR can be found in the current business community. In order to determine the WoRC of the investigated companies, their CSR reports were analysed for statements regarding social issues. The results of this analysis show that there is substantial variation in the amount of attention that each company gives to the four types of responsibilities. The average score and relatively high standard deviations - most standard deviations are higher than the average scores - indicate a considerable variation in the number of statements about each type of responsibility. In the case of the economic responsibilities, for instance, some companies made no statements at all, while others made up to 58 statements.

In the next phase of the research each company was assigned a narrow, average or broad role conception depending on their scores on the four types of responsibilities. The results of the research show that

TABLE VII

Correlation success - WoRC

Correlations

\begin{tabular}{|c|c|c|c|c|}
\hline & & & Role conception & Success \\
\hline \multirow[t]{4}{*}{ Spearman's rho } & Role conception & $\begin{array}{l}\text { Correlation coefficient } \\
\text { Sig. (2-tailed) }\end{array}$ & 1.000 & $\begin{array}{l}.335^{\star \star} \\
.005\end{array}$ \\
\hline & & $\mathrm{N}$ & 69 & 69 \\
\hline & Success & $\begin{array}{l}\text { Correlation coefficient } \\
\text { Sig. (2-tailed) }\end{array}$ & $\begin{array}{l}.335 \\
.005\end{array}$ & 1.000 \\
\hline & & $\mathrm{N}$ & 69 & 69 \\
\hline
\end{tabular}

$\star \star$ Correlation is significant at the 0.01 level (2-tailed) 
of the total investigated group of companies 52\% have a broad role conception regarding their social responsibilities. This means that these companies communicate an image in which they recognise their responsibility not only for economic and legal issues but also for ethical and philanthropic ones.

Although literature suggests that more and more multinational companies try to display a socially responsible image, $34 \%$ of the investigated group of companies pay very little or no attention at all to social issues. The remaining $12 \%$ of the investigated group of companies are regarded to have an average social role conception, indicating that these companies do pay attention to social issues, but not as extensively as the companies in the 'broad' group.

An important remark has to be made regarding the generalisation of the percentages of the 'wide', 'average' and 'narrow' groups that are presented in this section. The main goal of the research was to investigate whether narrow or wide role conceptions regarding social issues are related to a company's success in dealing with social demands. The research shows that there is a significant correlation between these two variables. The correlation coefficient of 0.335 indicates that the strength of the relationship can be interpreted as 'low to moderate'.

The results of this research show that of the four types of responsibilities only the attention to economic responsibilities and the attention to ethical responsibilities have a significant correlation with the success in dealing with social demands. The attention to legal and philanthropic responsibilities is not significantly related to this success.

When looking at the absolute amount of attention towards the different types of responsibilities it is clear that, on average, the companies pay less attention to legal and philanthropic responsibilities (Results, Table V); the companies have, on average, ten statements about economic and ethical responsibilities compared to three statements about legal responsibilities and four statements about philanthropic responsibilities.

Even though there is no obvious explanation for these findings, they lead to very interesting conclusions. Apparently, companies are less interested in reporting on their legal and philanthropic responsibilities. Furthermore the success in dealing with social demands appears not to be related to the amount of attention to these two types of responsibilities.

\section{Conclusions}

As is stated in the 'research problem' section earlier in this article the research project started from the point that Moir (2001) makes: "Whether or not business should undertake CSR, and what form that responsibility should take, depends on the economic perspective of the firm that is adopted." He argues that different companies can have different views on what their role in society should be and that this influences their involvement in social issues.

The goal of this research was to determine whether different role conceptions regarding social issues can be found in the current business community and whether this divergence leads to different outcomes when dealing with social demands. The results of the research indicate that more than half of the investigated companies communicate a broad role conception. Most companies present themselves as 'good corporate citizens' that have responsibilities that go beyond economic and legal obligations. However, there is still a significant amount of companies that communicate a narrow role conception by solely focusing on their economic and legal responsibilities. The first conclusion of this research therefore is that the suggested distinction between corporations' social role conceptions can indeed be found in the current business community.

Next the relationship between the two variables the WoRC and the success in dealing with social demands - was tested. Even though results of the research show that the relationship between the two variables is not strong, it does give indication that social role conceptions matter when dealing with social demands. Companies with broad social role conceptions score significantly better on their social reputation than companies with narrow role conceptions. The second conclusion of this research therefore is that the two variables in the research are indeed interrelated. Furthermore, the finding points to the practical conclusion that it does pay for companies to give attention to a wide range of responsibilities.

The traditional dominant industrial superpowers are mainly responsible for the development of CSR in both business and science. This research article also views the concept of CSR mainly from the 'western' perspective; most of the literature that is presented originates from the US and Europe. 
Hence, there is a good match between the selection of the research population and the used theoretical concepts.

An important question is, however, how the concept of CSR will develop in the future if the traditional economic powers are eventually redistributed. The emerging economies of traditional developing countries like China, India and Brazil can change the western dominance in the CSR debate. If more non-western-originated companies enter the top of the business community, different perspectives on what the responsibility of the business world to society is are likely to emerge.

The history of CSR shows that the popularity of the concept is steadily increasing and that more and more companies adopt it as a tool for building or maintaining their legitimacy in society. It will be interesting to see whether the distinction between the WoRC of businesses is going to disappear in the future and if an even larger majority of the international business community will adopt a wide range of issues as their social responsibilities.

\section{Acknowledgements}

We are grateful to Jörg Raab, Rob Jansen, Guido Palazzo and Luc van Liederkerke who commented on previous versions of this article.

\section{Notes}

1 This indicator is potentially biased towards the American perception of CSR; results by Fortune 500 are likely to differ from CSR classifications found in Europe or Japan. On the other hand, the latter measures corporate social performance (CSP), whereas this article focuses on CSR reputation. Therefore, we have to accept the potentially cultural bias as a limitation to this research.

\section{References}

Carroll, A. B.: 1979, 'A Three Dimensional Conceptual Model of Corporate Performance', The Academy of Management Review 4(4), 497-505.

Colvin, G.: 2001, Should Companies Care? Fortune, June 5, 2001.

Dawkins, J. and S. Lewis: 2003, 'CSR in Stakeholder Expectations: And Their Implication for Company Strategy', Journal of Business Ethics 44(2), 185-193.

Doane, D. and N. Abasta-Vilaplana: 2005, 'The Myth of CSR', Stanford Social Innovation Review 3(3), 22-29.

Gray, R., R. Kouhy and S. Lavers: 1995, 'Methodological themes Constructing a Research Database of Social and Environmental Reporting by UK Companies', Accounting, Auditing \& Accountability 8(2), 78-101.

Mah, A.: 2004, Uneasy Partnerships and Contradictions: Corporate Social and Environmental Responsibility, Proceedings of the 3rd Annual Global Studies Association Conference (Brandeis University).

Maignan, I. and O. C. Ferrell: 2003, 'Nature of Corporate Responsibilities Perspectives from American, French, and German Consumers', Journal of Business Research 56(1), 55-67.

Moir, L.: 2001, 'What do we Mean by Corporate Social Responsibility?', Corporate Governance 1(2), 16-22.

Sharfman, M.: 1996, 'The Construct Validity of the Kinder, Lydenberg \& Domini Social Performance Rating Data', Journal of Business Ethics 15(3), 287-296.

Stemler, S.: 2001, 'An Overview of Content Analysis', Practical Assessment, Research and Evaluation 7(17), 1-7.

Suchman, M. C.: 1995, 'Managing Legitimacy: Strategic and Institutional Approaches', The Academy of Management Review 20(3), 571-610.

de Vocht, A.: 2002, Basishandboek SPSS (Bijleveld Press, Utrecht).

Weber, R. P.: 1990, Basic Content Analysis 2nd Edition (Newbury Park, CA).

Organisation Studies, Tilburg University, P.O. Box 90153, 5000 LE, Tilburg, The Netherlands E-mail:t.goessling@uvt.nl 